\title{
BMJ Open A study protocol for a randomised controlled trial evaluating clinical effects of platelet transfusion products: the Pathogen Reduction Evaluation and Predictive Analytical Rating Score (PREPAReS) trial
}

\begin{abstract}
Paula F Ypma, ${ }^{1,2}$ Pieter F van der Meer, ${ }^{2}$ Nancy M Heddle, ${ }^{3}$ Joost A van Hilten, ${ }^{2}$ Theo Stijnen, ${ }^{4}$ Rutger A Middelburg, ${ }^{2,5}$ Tor Hervig, ${ }^{6}$ Johanna G van der Bom, ${ }^{2,5}$ Anneke Brand, ${ }^{2}$ Jean-Louis H Kerkhoffs, ${ }^{1,2}$ for the PREPAReS Study Group
\end{abstract}

To cite: Ypma PF, van der Meer PF, Heddle NM, et al. A study protocol for a randomised controlled trial evaluating clinical effects of platelet transfusion products: the Pathogen Reduction Evaluation and Predictive Analytical Rating Score (PREPAReS) trial. BMJ Open 2016:6:e010156

doi:10.1136/bmjopen-2015010156

- Prepublication history for this paper is available online. To view these files please visit the journal online (http://dx.doi.org/10.1136/ bmjopen-2015-010156).

Received 8 October 2015 Revised 23 December 2015 Accepted 5 January 2016

CrossMark

For numbered affiliations see end of article.

Correspondence to

Dr Paula F Ypma;

p.ypma@sanquin.nl

\section{ABSTRACT}

Introduction: Patients with chemotherapy-induced thrombocytopaenia frequently experience minor and sometimes severe bleeding complications. Unrestrictive availability of safe and effective blood products is presumed by treating physicians as well as patients. Pathogen reduction technology potentially offers the opportunity to enhance safety by reducing bacterial and viral contamination of platelet products along with a potential reduction of alloimmunisation in patients receiving multiple platelet transfusions.

Methods and analysis: To test efficacy, a randomised, single-blinded, multicentre controlled trial was designed to evaluate clinical non-inferiority of pathogen-reduced platelet concentrates treated by the Mirasol system, compared with standard plasma-stored platelet concentrates using the percentage of patients with WHO grade $\geq 2$ bleeding complications as the primary endpoint. The upper limit of the $95 \% \mathrm{Cl}$ of the non-inferiority margin was chosen to be $\mathrm{a} \leq 12.5 \%$ increase in this percentage. Bleeding symptoms are actively monitored on a daily basis. The adjudication of the bleeding grade is performed by 3 adjudicators, blinded to the platelet product randomisation as well as by an automated computer algorithm. Interim analyses evaluating bleeding complications as well as serious adverse events are performed after each batch of 60 patients. The study started in 2010 and patients will be enrolled up to a maximum of 618 patients, depending on the results of consecutive interim analyses. A flexible stopping rule was designed allowing stopping for non-inferiority or futility. Besides analysing effects of pathogen reduction on clinical efficacy, the Pathogen Reduction Evaluation and Predictive Analytical Rating Score (PREPAReS) is designed to answer several other pending questions and translational issues related to bleeding and alloimmunisation, formulated as secondary and tertiary endpoints.

Ethics and dissemination: Ethics approval was obtained in all 3 participating countries. Results of the

\section{Strengths and limitations of this study}

This study will be conducted as a large randomised controlled trial concerning Mirasol pathogen reduction technology; it will provide clinicians and blood banks with important information about this pathogen-reduction technique.

- The secondary outcomes of this study will offer opportunity to better predict bleeding episodes in thrombocytopaenic patients and insight into immunological refractoriness to platelet transfusions.

- The clinical relevance of WHO grade 2 bleeding is debated; however, WHO grade=2 bleeding is incorporated in the primary bleeding endpoint (grades 3 and 4 bleeding are obvious important bleeding complications).

- The control group of platelet concentrates contains different platelet doses due to countryspecific guidelines; subanalysis based on platelet content is feasible.

- The lack of blinding of the assessors collecting data on bleeding symptoms is a limitation to the study design.

main trial and each of the secondary endpoints will be submitted for publication in a peer-reviewed journal. Trial registration number: NTR2106; Pre-results.

\section{INTRODUCTION}

Patients with thrombocytopaenia due to myeloablative chemotherapy in the setting of serious and acute bone marrow disease are at risk of haemorrhagic complications. ${ }^{1}$ Platelet transfusions are extensively used for treatment and prophylaxis of bleeding in these patients. Bleeding and refractoriness to platelet transfusions are prominent issues in patient 
management, and clinicians face the challenge of choosing the most appropriate transfusion strategy. Meeting the demands of $24 \mathrm{~h}$ availability of safe platelet products is a logistic challenge, since the maximum storage time of platelets in the blood bank is 5 days. ${ }^{2}$ Platelets are stored at room temperature, which places them at higher risk of bacterial contamination as compared with other blood components. ${ }^{3}$ Extended storage of platelet concentrates for up to 7 days has been approved in Europe for clinical use, but requires a post-marketing surveillance phase and $100 \%$ bacterial testing. ${ }^{4}{ }^{5}$ Bacterial outgrowth to high titres, associated with longer storage times, has prompted a further search for techniques that warrant safe platelet products. Currently, in the Netherlands, $0.44 \%$ of all platelet products are found to be contaminated. ${ }^{6}$ Transfusiontransmitted bacterial infections with clinical consequences are rare, with estimated incidence of 1 in 70000 to 1 in 118000 cases. $^{7}$ Pathogen-reduction strategies aim to reduce the risk of bacterial contamination of stored platelet products. ${ }^{8}$ A recent review assessing the effectiveness of pathogen-reduced platelet products in general concluded that pathogen-reduced platelets did not differ from standard platelets with regard to clinically significant or severe bleeding complications or adverse reactions. ${ }^{9}$ Although the use of pathogen-reduced platelet products (PR-platelet concentrates) is not formally accepted as standard of care everywhere, gradually these products are being implemented in transfusion centres worldwide. Experts in the field of transfusion recently elucidated reasons for either implementing pathogen-reduction techniques or postponing decision-making on implementation. ${ }^{10}$ These reasons consist of the absence of regulatory approval, and concerns on safety and increment of pathogen-reduced platelets. ${ }^{10}$ Mirasol pathogen reduction technology (Mirasol PRT) is a treatment system designed for plasma and platelet products. This technology uses riboflavin, a naturally occurring vitamin $\mathrm{B}_{2}$, which interacts with nucleic acids leading to a chemical reaction when exposed to ultraviolet (UV) light. ${ }^{11}$ Riboflavin-based photochemical treatment has been shown to be effective against a broad range of pathogens. ${ }^{12}{ }^{13}$ In addition to reducing the infectious risk of viruses and bacteria for which blood is currently tested, this technology also offers a safety benefit by protecting against unknown and/or emerging pathogens, or pathogens that cannot be detected otherwise in an early phase of infection (window phase). Until now, only one randomised study evaluating Mirasol PRT, comparing corrected count increments (CCIs) of treated versus untreated apheresis or buffy coatderived plasma-platelet concentrates, has been performed. ${ }^{14}$ This trial showed acceptable $1 \mathrm{~h}$ CCIs for both methods of preparation and no difference in platelet or red cell usage, suggesting no increase in bleeding tendency. Besides effective pathogen reduction, another important (pre)clinical premise concerning Mirasol treatment is potential effectiveness in reducing alloantibody formation. Indeed, the 'trial to reduce alloimmunisation to platelets study group' showed evidence in patients suffering from acute myeloid leukaemia that UV-B illumination of platelets is equally effective as leukofiltration in preventing generation of alloantibodies, as well as alloantibody-mediated refractoriness to platelets. ${ }^{15}$

\section{Rationale}

Policymakers, product providers and investigators agree that substantial changes in platelet production, such as pathogen reduction technologies, should also be validated for their clinical efficacy, including an assessment of bleeding. The Pathogen Reduction Evaluation and Predictive Analytical Rating Score (PREPAReS) study was initiated to investigate Mirasol-treated platelet products for clinical efficacy. The research question that is addressed is summarised in figure 1 . The aim is to describe here the design of the PREPAReS trial and provide rationale for the design elements that were incorporated into this study.

\section{Objectives}

Primary objective

The primary aim of this study is to assess the noninferiority of PR-plasma-platelet concentrates (PCs)

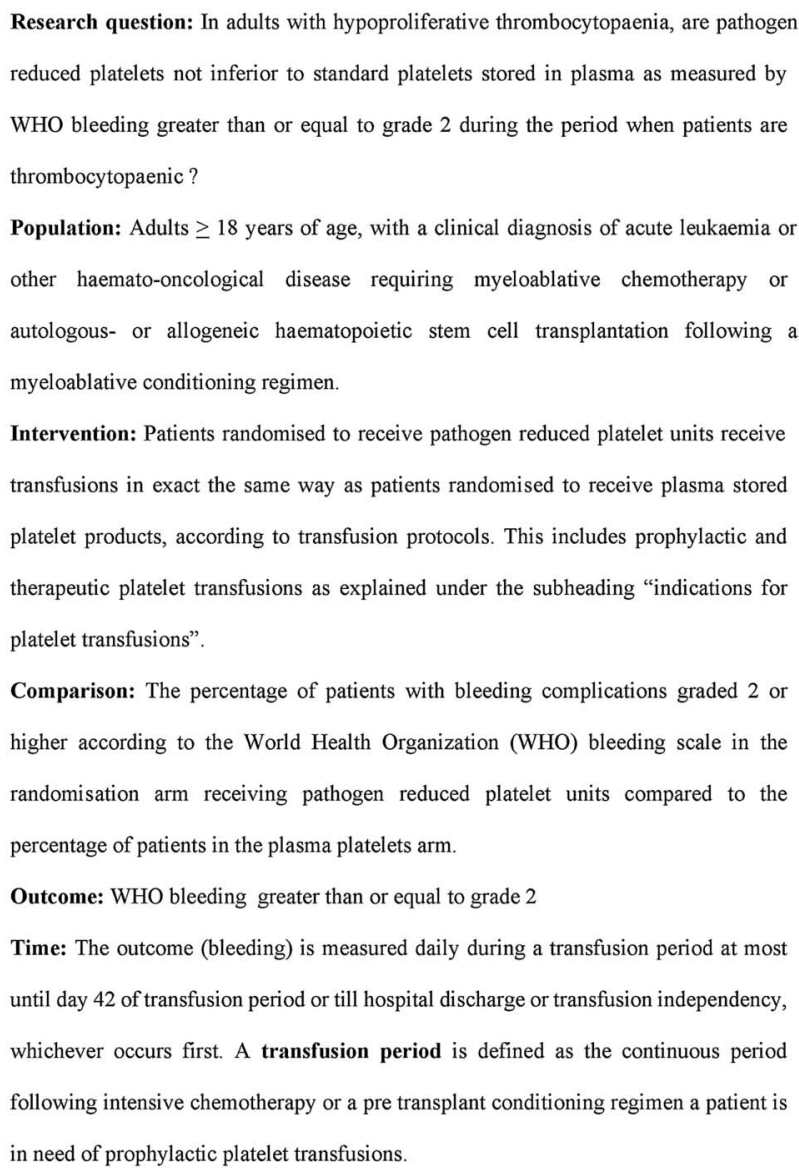

Figure 1 Pathogen Reduction Evaluation and Predictive Analytical Rating Score (PREPAReS) research question (PICOT format). 
compared with plasma-PCs in terms of WHO bleeding complications $\geq$ grade 2 (expressed as percentage of patients) in haemato-oncological patients with thrombocytopaenia during one transfusion episode.

\section{Secondary objectives}

1. To assess the transfusion failures defined as $1 \mathrm{~h} \mathrm{CCI}$ $<7.5$ and $24 \mathrm{~h}<4.5,1$ and $24 \mathrm{~h} \mathrm{CI}$ and CCI of all platelet transfusions.

2. To assess the percentage of days that bleedings >WHO grade 2 occur.

3. To evaluate whether clinical factors interact with the different study products leading to a difference in platelet refractoriness.

4. To assess the safety (incidence of adverse reactions).

5. To assess the transfusion requirement (red cells and platelets).

6. To assess the transfusion interval.

7. To assess the rate of human leucocyte antigen (HLA) alloimmunisation.

8. To evaluate whether in vitro measures relate to in vivo outcome measures as the $1 \mathrm{~h}$ and the $24 \mathrm{~h}$ CCI.

9. To establish the relation between albuminuria and bleeding tendency.

10. To establish whether transmission of commensal viruses can be prevented by the Mirasol treatment.

\section{METHODS AND ANALYSIS}

\section{PREPAReS trial design}

The PREPAReS study is a randomised multicentre trial using a parallel arm design. Three countries involving 10 centres are participating in PREPAReS. In the Netherlands, there are three academic centres and one non-academic hospital participating. In Norway, one academic centre participates and in Canada, one academic centre and four general hospitals participate. In all of these hospitals, there are facilities for haematological intensive care for patients with acute leukaemia, and autologous and/or allogeneic stem cell transplantation for haemato-oncological diseases. Sanquin Blood Supply, the Dutch Blood Bank, is the study sponsor. Patient enrolment started in 2010 and is expected to end in 2016. The study was approved by a central ethical committee as well as the local Research Ethics Boards (REBs) of the participating sites. Figure 2 summarises the design of the trial and each of the trials aspects is described in detail below.

\section{Eligibility criteria}

Patients aged 18 years or older are eligible for inclusion in the study; they are expected to require at least two platelet transfusions during a period of profound thrombocytopaenia. This may be following intensive chemotherapy or a conditioning regimen prior to haematopoietic stem cell transplantation, due to aplastic anaemia or a result of the bone marrow disease crowding out megakaryopoiesis. Exclusion criteria include microangiopathic thrombocytopaenia and idiopathic thrombocytopenic purpura (ITP); bleeding grade $>2$ at randomisation; known immunological refractoriness to platelet transfusions; HLA and/or HPA alloimmunisation or clinical relevant autoantibodies; pregnancy; indications to use hyperconcentrated platelets; prior treatment with pathogen-reduced blood products; known allergy to riboflavin or its photoactive products. Sites that routinely perform HLA/platelet antibody screening when immunological refractoriness is suspected will base this decision on a positive screening test result. Sites that do not routinely carry out this screening will base this decision on clinical judgement. With regard to patients presenting with a bleeding condition of grade $>2$ before enrolment, a template was designed to support decision-making, primarily enabling the enrolment of patients with old bruises (figure 3). Patients previously treated with pathogen-reduced platelet products using other technologies are also excluded.

\section{Randomisation}

Patients who meet the eligibility criteria are randomised to receive either standard plasma-stored, or Mirasol-treated platelet products, during a transfusion period (for definition of 'transfusion period': figure 1). Randomisation takes place using a web-based tool, as part of ProMISe (Project Manager Internet Server). The ProMISe system, developed at the Leiden University Medical Center, provides custom-made databases for scientific medical research as well as an application for online data entry, quality checks and reporting. The treatment allocation scheme is created within ProMISe and is generated by the computer, ensuring concealment of treatment allocation. The randomisation method uses permuted blocks of variable size, randomly varying from 2 to 6 participants. Stratification factors in the randomisation are: centre, diagnosis (acute myeloid leukemia (AML) vs no AML) and treatment phase (transplant vs no transplant). ${ }^{16}$ Patients are randomly assigned to the treatment allocation at the time that they are expected to require their first platelet transfusion. All eligibility criteria will be checked with an electronic checklist during randomisation. Randomisation will be requested by the staff member responsible for recruitment. Each patient will be given a unique patient study number, which will be given immediately by the randomisation provider (ProMISe) and confirmed by email. This email is sent to the staff member requiring randomisation as well as to the general PREPAReS email address, controlled by the principal investigator. Patients may be re-randomised in a subsequent transfusion period (see figure 1) following a next intensive chemotherapy course or a pre-transplant conditioning regimen and the statistical analysis will account for multiple randomisations per individual. ${ }^{17}$

\section{Treatment arms}

All platelet products are produced by local blood suppliers (Sanquin Blood Bank in the Netherlands, 
Figure 2 PREPAReS trial

design. The flow chart

summarises the design of the

PREPAReS trial; eligible patients

may be enrolled more than once, for example, when they receive consolidation chemotherapy.

*See also figure 3. PR, pathogen-reduced; PREPAReS Pathogen Reduction Evaluation and Predictive Analytical Rating Score.

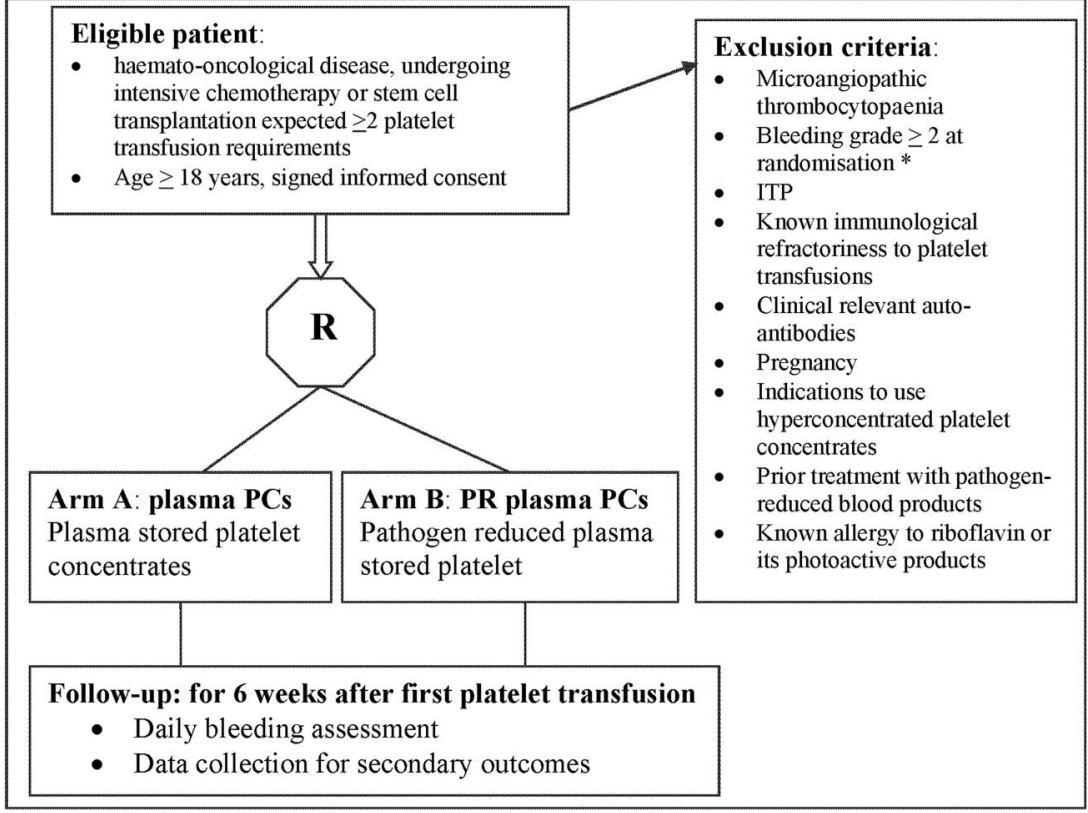

Haukeland University Blood Bank in Norway and Canadian Blood Services in Canada). Platelet concentrates are all prepared from pooled buffy coats and are re-suspended in plasma. The pooled platelet concentrates are leukoreduced by filtration. All platelet products are stored with gentle agitation at $20-24^{\circ} \mathrm{C}$ up to 7 days in the Netherlands and Norway, and for a maximum of 5 days in Canada. Patients randomised to the standard platelet product arm of the study receive platelet products prepared in this manner.

The platelet products transfused to patients in the pathogen-reduced arm of the study are prepared as follows: $500 \mu \mathrm{M}$ riboflavin is added to the leukoreduced plasma-platelet concentrates within $28 \mathrm{~h}$ of platelet collection, mixed and exposed to UV-B light (wavelength 280-315 nm) for 5-10 min (depending on the volume of the platelet concentrate) with constant agitation at $120 \mathrm{rpm}$, giving a total dose of $6.2 \mathrm{~J} / \mathrm{mL}$. Following treatment, the platelets are stored in the same way as the untreated platelets, making sure that the products are not exposed to direct daylight. In all participating centres, a standardised automated culture method is used to detect bacterial contamination of the platelet product. $^{18}$

Products are $\gamma$-irradiated if indicated by the requesting centre, even though the Mirasol procedure is licensed for white cell inactivation to prevent graft versus host disease, making $\gamma$-irradiation unnecessary. The rationale for $\gamma$-irradiation in this trial reflects a logistical concern that two different policies of irradiation based on the treatment arms of the study could increase the risk of error. It could result in patients in the standard treatment arm incorrectly receiving non-irradiated products, or patients in the treatment arm receiving nonirradiated products in case of an off protocol transfusion.
Table 1 shows characteristics of the platelet products in the participating countries. In Canada, platelet concentrates are routinely prepared from four buffy coats, with on average $300 \times 10^{9}$ platelets per unit. The SPRINT trial had shown that pathogen-reduced platelet units with fewer than $300 \times 10^{9}$ per unit were associated with a significantly shorter transfusion interval and lower CCIs (though not an increased bleeding risk) compared with untreated platelet concentrates with $<300 \times 10^{9}$ platelets per unit. ${ }^{1920}$ Since there was a chance that the platelet content in a four buffy coat pool would be below this threshold, the Canadian sites provided a five buffy coat platelet pool for patients allocated to the PR arm, increasing the number of platelets by $25 \%$. The Canadian hospitals wanted to maintain four buffy coats in the control arm, as this is the current standard of practice to which the PR arms should be compared. Differences in platelet numbers could potentially lead to a bias in the study. Therefore, before the final decision was made, quality control data from Canada and the Netherlands for the year 2011 were compared. The Dutch untreated units from five buffy coats $(n=5068)$ contained, on average, $380 \pm 55 \times 10^{9}$ platelets. Treated units from five buffy coats $(n=347)$ contained 366 $\pm 55 \times 10^{9}$, that is, about $5 \%$ lower than untreated ones. Canadian untreated platelet concentrates from four buffy coats $(n=1302)$ had an average of $312 \pm 54 \times 10^{9}$ platelets. Therefore, five buffy coats would theoretically give $390 \times 10^{9}$ platelets, but with the $5 \%$ decrease due to the handling associated with Mirasol treatment, the expected average would come to $371 \pm 64 \times 10^{9}$ platelets. Assuming that Canada would include one-third of the patients, and the Netherlands and Norway two-thirds, the overall distribution of platelet numbers per concentrate was estimated. This estimation was based on the following facts: platelet concentrates in the untreated 
Figure 3 Inclusion in the study in case of a bleeding complication. Template for decision-making in case of a bleeding complication at presentation before enrolment of the Pathogen Reduction

Evaluation and Predictive

Analytical Rating Score (PREPAReS) trial. Bleeding grade is based on $\mathrm{WHO}$ bleeding scale.

\begin{tabular}{|l|l|}
\hline Bleeding condition at screening & Site action for enrolment \\
\hline \hline Active grade $\geq 2$ bleeding & $\begin{array}{l}\text { Exclude, and re-evaluate after bleeding } \\
\text { has resolved }\end{array}$ \\
\hline $\begin{array}{l}\text { Grade } 2 \text { bleeding that occurred in the day(s) } \\
\text { before screening, but has resolved with no active } \\
\text { bleeding for at least } 24 \text { hours prior to screening } \\
\text { Exception: Skin / soft tissue bleeding grade } 2\end{array}$ & Include \\
\hline \hline $\begin{array}{l}\text { Existing grade 2 skin / soft tissue bleeding that } \\
\text { occurred in the day(s) before screening, and are } \\
\text { still visible at the day of screening }\end{array}$ & Include \\
\hline $\begin{array}{l}\text { A resolved grade } 3-4 \text { bleeding episode in the } \\
\text { day(s) before screening }\end{array}$ & Patients can be included after 14 days \\
\hline
\end{tabular}

group were derived from four buffy coats for Canada and Norway, and five buffy coats for the Dutch sites; in the Mirasol group, they were four buffy coats for Norway and five buffy coats for all other sites. Under these conditions, it was calculated that the platelet counts would largely overlap, although in the untreated group, about $23 \%$ would contain $<300 \times 10^{9}$ vs $7 \%$ in the Mirasol group. In the SPRINT trial, $12 \%$ of the platelet concentrates in the control group contained $<300 \times 10^{9}$ platelets versus $20 \%$ in the pathogen-inactivated group. $^{19}$ Therefore, we accepted that, in Canada, untreated platelet concentrates were made from four buffy coats, while in the Mirasol-treated group, they were made from five

Table 1 Characteristics of platelet products in three participating countries in the PREPAReS trial

\begin{tabular}{|c|c|c|c|}
\hline & \multicolumn{3}{|c|}{$\begin{array}{l}\text { Country Participating } \\
\text { in PREPAReS }\end{array}$} \\
\hline & $\begin{array}{l}\text { The } \\
\text { Netherlands }\end{array}$ & Norway & Canada \\
\hline Blood supplier & $\begin{array}{l}\text { Sanquin } \\
\text { Blood Bank }\end{array}$ & $\begin{array}{l}\text { Haukeland } \\
\text { University } \\
\text { Blood } \\
\text { Bank }\end{array}$ & $\begin{array}{l}\text { Canadian } \\
\text { Blood } \\
\text { Services }\end{array}$ \\
\hline $\begin{array}{l}\text { Anticoagulant used } \\
\text { for whole blood } \\
\text { collection }\end{array}$ & CPD & CPD & CPD \\
\hline $\begin{array}{l}\text { Method of platelet } \\
\text { preparation }\end{array}$ & Buffy coat & Buffy coat & Buffy coat \\
\hline $\begin{array}{c}\text { Standard pool size of } \\
\text { Plasma platelets }\end{array}$ & 5 & 4 & 4 \\
\hline $\begin{array}{l}\text { Pathogen-reduced } \\
\text { platelets }\end{array}$ & 5 & 4 & $\begin{array}{l}4 \\
5\end{array}$ \\
\hline Bacterial testing & Yes & Yes & Yes \\
\hline Storage solution & Plasma & Plasma & Plasma \\
\hline Duration of storage & 7 days & 7 days & 5 days \\
\hline
\end{tabular}

buffy coats. Subanalysis based on platelet content is feasible. Moreover, a higher platelet dose may offset part of the lower platelet increments seen with Mirasol-treated platelet concentrates. ${ }^{14}$

\section{Indications for platelet transfusions}

Indications for platelet transfusions are distinguished into platelet count-related prophylaxis (PP), intervention-related prophylaxis (IP) and treatment of bleeding (TB). For each transfusion, the indication is recorded. The Dutch transfusion guidelines are used as guidance for the indication of platelet transfusions, these imply: trigger for PP $10 \times 10^{9} / \mathrm{L}$; for IP $50 \times 10^{9} / \mathrm{L}$; and for TB until bleeding stops or up to a platelet count of $100 \times 10^{9} / \mathrm{L}$. When bleeding complications occur intracranially, in the retina or in any other vital organ, the advised platelet count is $>100 \times 10^{9} / \mathrm{L}{ }^{21}$ The treating physician determines if or when a transfusion is ordered.

\section{Outcomes (primary and secondary)}

The primary outcome for the study is bleeding greater than or equal to WHO grade 2 (WHO). Earlier comparative platelet transfusion studies concerning platelet additive solutions, and even the Mirasol system for pathogen inactivation, used CCIs as primary outcome measure. ${ }^{14}$ The CCI, however, is inadequate as a surrogate marker for the occurrence of bleeding symptoms. $^{22}{ }^{23}$ There is general agreement that substantial changes in platelet production and processing should not only be validated by CCI measurement, but, also, clinical validation for their haemostatic effectiveness is needed. Haemostatic assessment ideally is performed using a consistent and well-described manner. ${ }^{24}$ Several large randomised controlled trials (RCTs) that were published in recent years used the WHO bleeding scale. ${ }^{25-28}$ The WHO bleeding scale can be regarded as a grading method that classifies the seriousness of bleeding. In the 
WHO bleeding scale, grade 0 is absence of bleeding; grade 1 bleeding generally is considered not to be clinically relevant, in the grade 2 bleeding category, bleeding of variable clinical relevance is encountered (skin, mucosal membranes, bleeding at invasive sites, etc), whereas grades 3 (bleeding requiring red cell transfusions) and 4 bleeding (central nervous system bleeding and fatal bleeds) are the most serious. In a pilot study where daily bleeding was assessed in the Dutch centres that currently participate in the PREPAReS, we found that $54 \%$ of patients present with grade $>2$ bleeding at some point in their clinical course. ${ }^{29}$ As this is comparable to the STOP trial, published in 2009, we used these pilot data for the power calculation of the PREPAReS. ${ }^{25}$

Secondary outcomes contribute to the evaluation of non-inferiority of pathogen-reduced platelet products in this patient population: the frequency of $1 \mathrm{~h}$ and $24 \mathrm{~h}$ post-transfusion platelet increment failures (defined as $1 \mathrm{~h} \mathrm{CCI}<7.5$ and $24 \mathrm{~h} \mathrm{CCI}<4.5$ ), the percentage of days that bleedings $\geq \mathrm{WHO}$ grade 2 occur, the incidence of adverse reactions, the transfusion requirement of red cells and platelets, and the platelet concentrate transfusion interval, and the incidence of HLA alloimmunisation. The evaluation of whether in vitro measures relate to in vivo outcome measures as the $1 \mathrm{~h}$ and the $24 \mathrm{~h}$ CCI is also defined as secondary outcome, and is incorporated in several tertiary outcomes as explained ahead.

\section{Tertiary outcome measures; linking in vitro quality tests to} in vivo outcomes

The large cohort of patients randomised in the PREPAReS being closely watched for bleeding symptoms, creates possibilities for additional research questions. Outcome measures, focusing on the connection of preclinical and clinical outcomes with respect to safety issues (decrease of microbial transmission and HLA antibody formation) as well as other translational aspects, are addressed in the PREPAReS trial. Prediction of individual bleeding episodes on clinical grounds, or with the aid of laboratory measurements, remains a blind spot in the aim of maximal prevention strategies.

\section{In vitro platelet quality testing and relation with $\mathrm{CCl}$}

Currently, provided the $\mathrm{pH}$ is above the threshold for product release $\left(\mathrm{pH}_{22} \circ>6.2\right)$, there are no in vitro measurements available that accurately predict platelet recovery, survival or haemostatic function in platelet concentrates. ${ }^{30-32}$ A combination of individually wellestablished metabolic, activation and functional parameters of platelet concentrates, combined into one 'rating score', may predict either the $1 \mathrm{~h}$ and/or the $24 \mathrm{~h}$ CCI. For such an in vitro rating value, we selected assays that can be performed shortly before transfusion of the platelet concentrates. We selected three parameters for this rating system, each of which could play an independent role in predicting in vivo effectiveness of stored platelet concentrates, for reasons discussed below. ${ }^{33}$ First, we considered CD62P expression, an
Table 2 Rating score for quality testing platelet concentrates

\begin{tabular}{llll}
\hline Score in vitro test & 2 points & 1 point & 0 points \\
\hline CD62P expression & $<20 \%$ & $20-30 \%$ & $>30 \%$ \\
Annexin A5 binding & $<10 \%$ & $10-20 \%$ & $>20 \%$ \\
Lactate concentration & $<10 \mathrm{mM}$ & $10-20 \mathrm{mM}$ & $>20 \mathrm{mM}$ \\
\hline
\end{tabular}

activation marker, on the platelet surface. A higher CD62P expression has been associated with enhanced platelet clearance from the circulation. ${ }^{34-37}$ Second, impaired platelet survival in animals was found to be associated with the apoptosis marker annexin A5 binding. ${ }^{38}{ }^{39}$ The third assay is the lactate concentration (as surrogate for lactate production) as a low lactate production rate is considered a good indicator of mitochondrial function. ${ }^{31} 4041$ The in vitro outcomes of each of these three parameters are scored from 0 to 2 , where 0 points would indicate a poor quality and 2 points a good quality, rated on an arbitrarily chosen linear basis. The combined rating then results in a value between 0 (poor quality) and 6 (optimal quality; table 2). By relating the in vitro rating scores with CCI values and haemostatic assessment data of the transfusion day, and the day after, the relation between this combination of metabolic (lactate concentration), activation (CD62P) and apoptosis (annexin A5) parameters of transfused platelet concentrates, and the usefulness of combining these into one 'rating' value, will be evaluated. Other laboratory tests for platelet responsiveness of the product will be performed and linked to clinical outcome, including thromboelastography and dynamic light scattering (ThromboLUX, LightIntegra, Canada). ${ }^{42}$ We apply the same tests also on patient samples prior to and after transfusion, to investigate if there is an improvement in these platelet function assays and how that relates to the tests performed on that platelet concentrate. The research staff performing daily bleeding assessments is blinded for the outcomes of the in vitro tests of the product and of patient samples.

\section{HLA antibodies}

The Mirasol treatment not only inactivates proliferation of residual contaminating white blood cells in platelet products preventing graft versus host disease, but also impairs the antigen-presenting potential of treated leukocytes. Animal studies contribute to the hypothesis that the Mirasol procedure could play a role in reducing the alloimmunisation and induce tolerance to a subsequent allograft. ${ }^{43-47}$ To further investigate these assumptions in the current study, samples are obtained from patients who are negative for HLA antibodies prior to transfusions, and analysed to investigate de novo or boostered formation of HLA antibodies during a follow-up period. These samples are collected weekly during hospitalisation up until day 28 , and then on day 56 , and tested in 
the Luminex-based assay for presence of HLA antibodies. ${ }^{48}$ In a selected cohort of primed and unprimed patients, following the first on-protocol transfusion, the $1 \mathrm{~h}$ samples are analysed for induction of HLA class II molecules on T-cells of the donor (if detectable) and recipient, and at day 56, blood is collected and frozenprocessed for evaluation of persisting donor cells.

\section{Endothelial damage}

Cytotoxic therapy for haemato-oncological disease plays a central role in the occurrence of a bleeding event. ${ }^{49-51}$ Maintenance of vascular integrity is important to prevent microvascular and macrovascular bleeding symptoms. Endothelial damage is a presumed mechanism for increased (transfused) platelet consumption. ${ }^{52}$ A subset of patients included in the PREPAReS trial (this depends on hospital participation) undergo serum C reactive protein and urine testing for albumin twice weekly. These laboratory markers for endothelial damage ${ }^{5354}$ will be analysed in relation to the extent of the bleeding tendency patients develop during the platelet transfusion period.

\section{Tests for commensal viruses}

The pathogen reduction technology applied in the PREPAReS study aims to reduce the transmission of pathogens. The actual risk of viral transmission is in the order of 1 in 1 million or less, and for clinically relevant transmission of bacteria about 1 in 70000 to 1 in $118000 .{ }^{755}$ Hence, the PREPAReS trial is not powered to detect prevention of transmission of pathogens. Commensal viruses in the blood supply are not screened for, as they are present in healthy blood donors, and are thought to be non-pathogenic, albeit this may not be the case for (premature) infants and immunocompromised patients. Because of their universal presence in humans, commensal viruses can therefore serve as surrogate markers for pathogen-reduction efficacy. Transmission of commensal viruses during transfusion can be most efficiently tracked using the highly genetically diverse commensal anelloviruses, of which numerous strains can be readily distinguished by their distinct DNA sequences. Genetic comparisons of the strains of anelloviruses in donor and recipient samples, therefore, offer a sensitive system to confirm viral transmission during transfusion and to detect its elimination in patients who receive Mirasol-treated platelet units. ${ }^{56}$

\section{Assessment of bleeding}

During the transfusion period, patients are screened for bleeding every day by a member of the study team. Every assessor is trained by an instruction slide set on the study website, which discusses usual and unusual or debatable bleeding sites and presentations, followed by a test. The assessments are performed by physical examination and patient interviews, as well as checking hospital medical and nursing charts. In Canada, a validated patient self-assessment form is used on weekends, ${ }^{57}$ with additional follow-up at the beginning of the week by reviewing the patient's medical record and communicating with the care givers who were on service over the weekend period, to ascertain if bleeding has occurred.

\section{Blinding}

Because the Mirasol-treated platelet products show a colour difference that does not allow proper blinding to the treatment arm, the study is not blinded for research personnel evaluating bleeding signs and symptoms. Nurses involved in giving the transfusion or assisting with data collection other than bleeding may be aware of the randomisation results. The actual allocation must not be disclosed to the staff members responsible for the adjudication process, nor to the monitors and the sponsor. In none of the corresponding patient documents is the allocation disclosed.

\section{Grading the bleeding}

The grade of bleeding is assigned later by three independent adjudicators blinded to the patient's treatment allocation, based on the specified WHO bleeding scale. ${ }^{26}$ If discrepancies occur, a consensus meeting is organised to make a final decision on the bleeding grade. In addition, an automated algorithm for computer adjudication on consecutive haemostatic assessment data sets was developed, and showed an excellent relationship with 'human' adjudication. ${ }^{58}$ Human and computerised adjudication is performed independently once the data manager has given permission to adjudicate a subsequent series of 60 participants with complete data. In the event that discrepancies occur between the manual and computerised adjudication, agreement arrives through consensus. The blinded adjudicators also answer any questions or issues concerning unclear bleeding symptoms from participating sites through the study by email.

\section{Adverse events}

Adverse events are, according to the definitions, any unfavourable or unintended event affecting patients on study. In cases of prolongation of hospitalisation, death or significant clinical sequelae, these events are defined as serious adverse events (SAEs), the occurrence of which the study sponsor (Sanquin) and the Data Safety Monitoring Board (DSMB) will be informed at short notice. During protocol treatment, all deaths, all SAEs that are life-threatening and any unexpected SAE must be reported to the Sanquin data manager using the SAE web form within $48 \mathrm{~h}$ of the initial observation of the event. The protocol treatment period is defined as the period from the first study-related platelet transfusion until 30 days after the last study-related platelet transfusion, or until the start of another systemic anticancer treatment cycle, if that occurs earlier. All details should be documented on the SAE and death report. Reports will also be sent to the local Canadian REBs and to Health Canada, according to pre-established criteria. 
Further, any death (regardless of cause) that has come to the attention of the study staff, occurring more than 30 days after the last study-related platelet transfusion, must be reported to the Sanquin data manager using the death report web form.

Safety aspects of the study are closely watched by the DSMB, which receives unblinded data for its judgement. In the case of a suspected relation of the SAE to the pathogen-reduction technique, Terumo blood component technology (Terumo BCT) is notified.

\section{Data management}

In the PREPAReS trial, data are collected during a transfusion episode, as defined (figure 1). Data collection is performed by trained local research staff and data entry in the ProMISe database is completed in a standardised fashion from two central research locations in Canada and the Netherlands. Other participating centres in the Netherlands and Canada as well as the Norwegian centre send their paper case report forms (CRFs) to the data entry site. A central data manager performs and monitors data entry, and looks after timely CRF delivery. Data on the CRF will include at least: scores of bleeding, baseline observations at entry, follow-up observations, observations before, during and after platelet and red cell transfusions, adverse transfusion reactions, and the parameters needed for calculating 1 and $24 \mathrm{~h}$ CCIs. Any other parameters necessary to evaluate the study endpoints and reason for end of protocol treatment are also documented.

\section{End of protocol treatment}

Reasons for going off protocol are:

- Transfusion independency $>7$ days or hospital discharge, whichever occurs first.

- Patient non-compliance (especially refusal to continue; the reason for discontinuation must be recorded in the source documentation and the Study Exit CRF).

- Intercurrent death.

- Reasons for going off protocol treatment, but with full study monitoring, including daily scoring of bleeding, are:

- Serious adverse transfusion reactions necessitating other products;

- Immunological refractoriness.

\section{Sample size and rationale for non-inferiority}

The PREPAReS study is designed on a hypothesis of non-inferiority. Apart from the superior safety profile of the product to date, ${ }^{59}$ the effectiveness of the product to prevent bleeding may be less than that of the control product, to some extent. Previous studies ${ }^{25} 2729$ indicated that, in this specific patient group, on average, $50 \%$ of patients with thrombocytopaenia exhibit bleeding complications $\geq$ grade 2 at any time while on study. Based on discussions with clinicians and on the basis of earlier published studies, ${ }^{26}$ the investigators agreed that up to a $12.5 \%$ increase in grade 2 or greater bleeding would be acceptable to still claim non-inferiority of the PR platelet product. Thus, non-inferiority will be concluded when the upper limit of the two-sided 95\% CI for the difference between the risk of a $\geq$ grade 2 bleeding in the Mirasol group compared with the control group is below $12.5 \%$. Under the assumption of $50 \%$ risk in both groups, the required number of patients to demonstrate non-inferiority with $80 \%$ power is 618 (309 per arm), taking into account the stopping rule as well as a 7\% drop out of patients. For safety reasons, interim analyses are planned in this study after every 60th inclusion. A flexible stopping rule based on $\alpha$ and $\beta$ spending functions was designed, allowing stopping for noninferiority or futility. The (unblinded) DSMB will, at each interim analysis, either give the green light for continuation or not; the study team remains blinded.

\section{Statistical analysis}

\section{Primary outcome}

The primary effect parameter is the difference in the probability of a WHO bleeding complication $\geq$ grade 2 during one transfusion episode for pathogen-reduced platelet concentrates compared with standard plasma-stored platelet concentrates. Patients can contribute more transfusion episodes to the study and the outcomes of different transfusion periods may be correlated within patients. Furthermore, the probability of a $\geq$ grade 2 bleeding might depend on the number of the episode within a patient. The primary effect parameter is estimated according to a generalised estimating equation (GEE) approach using a generalised linear model with identity link and independence working correlation. Covariates in the model will be the treatment group, the episode number (dichotomised as first or later) and the interaction between these two covariates. The primary treatment effect is then calculated as a weighted mean of the effect in first episodes and in later episodes, where the weights are proportional to the numbers of first and later episodes in the study. If the upper bound of the two-sided $95 \%$ CI is $<12.5 \%$, the reduced platelet treatment will be concluded to be noninferior to standard plasma-stored platelet concentrates.

\section{Secondary outcomes}

We only briefly describe the analysis of the most important secondary outcomes. Transfusion failures are defined as $1 \mathrm{~h}$ CCI $<7.5$ and $24 \mathrm{~h}$ CCI $<4.5$, where the $1 \mathrm{~h}$ and $24 \mathrm{~h} \mathrm{CCI}$ are defined as:

$$
\mathrm{CGI}_{1 / 24 \mathrm{~h}}=\frac{\begin{array}{c}
\text { post- }- \text { pretransfusion count }\left(\mathrm{x} 10^{9} / \mathrm{L}\right) \\
\times \text { body surface area }\left(\mathrm{m}^{2}\right)
\end{array}}{\text { transfused number of platelets }\left(\times 10^{11} / \mathrm{L}\right)}
$$

Per episode, the failure rates are calculated as the number of failed transfusions as proportion of the total 
number of transfusions. Next, the failure rates are analysed by a GEE approach analogous to the primary outcome analysis.

The $1 \mathrm{~h}$ and $24 \mathrm{~h}$ CCI will be analysed with a fully specified linear mixed model, taking into account the correlations between transfusions within episodes as well as between episodes within patients. The percentage of days that bleedings $\geq$ WHO grade 2 occur per episode will be analysed following the GEE approach, as for the primary outcome. The rate of alloimmunisation will be analysed using the log-rank test.

\section{Monitoring}

The study will have monitoring for quality and regulatory compliance. In the Netherlands and Norway, monitoring will be performed by Sanquin. In Canada, monitoring of the participating sites and McMaster Transfusion Research Program (MTRP) (acting as the Canadian Clinical Research Officer (CRO)) will be performed through a contract with an external company that specialises in monitoring of clinical trials. The frequency depends on inclusion rates, questions and pending issues from earlier audits: once or twice a year.

\section{Ethics and dissemination}

Ethics approval was first obtained in the Netherlands at the Medical Ethics Committee South West Holland (The Hague, The Netherlands). They judged the study design, ethics, interim analyses, the allowed level of non-inferiority and safety rules. On approval, the study was started in the HAGA Teaching Hospital in The Hague. Additional regional approval was obtained for the remaining three Dutch hospitals. In Norway, ethics approval was obtained from the Regional Committee for Medicine and Health Research Ethics (region West, Bergen, Norway). In Canada, ethics approval was obtained at each of the five sites from the local REB. The trial is registered with the Netherlands Trial Register NTR2106.

A manuscript with the results of the primary study will be published in a peer-reviewed journal. Separate manuscripts will be written on each of the secondary aims, and these will also be submitted for publication in peerreviewed journals.

On completion of the trial, and after publication of the primary manuscript, data requests can be submitted to the researchers at the Center for Clinical Transfusion Research, Sanquin Research, Leiden, The Netherlands.

\section{DISCUSSION}

Supportive care of patients with life-threatening haemato-oncological disease is an important issue. Photochemical pathogen reduction contributes to the risk reduction of transfusion with regard to transmitted infections. ${ }^{12}$ It remains, however, unclear whether this improved safety is not outweighed by the potentially reduced clinical efficacy of PRT platelets, that is, decreased post-transfusion increments, increased platelet product consumption and even increased bleeding risk. ${ }^{9}$ With regard to Mirasol-treated platelets, a recent RCT showed decreased post-transfusion increments but did not find an increase in bleeding complications. ${ }^{14}$ The main goal of the PREPAReS study is to demonstrate noninferiority of Mirasol-treated platelets as compared with standard untreated platelets, using the percentage of patients with $\geq$ WHO grade 2 bleeding as primary outcome. Alloimmunisation as well as in vitro platelet quality testing related to clinical outcome are two other important cornerstones of this study. This study will collect day-to-day data of over 600 patients, 2000 platelet transfusions and 24000 days of follow-up, allowing for several other important issues, for instance the capacity of the current WHO system to grade bleeding complications in predicting major bleeding complications, the possibility of testing other bleeding scales and serving as a platform for several site studies including albuminuria as a predictor for vascular damage, increased platelet consumption and, perhaps, bleeding. ${ }^{60-62}$

The potential reduction of alloimmunisation through the use of Mirasol-treated platelets would be of additive beneficial value, potentially even more clinically significant in comparison to the reduction of transfusion transmitted infectious diseases. Last but not least, linking in vitro platelet product quality markers potentially enables us to improve the preclinical testing of novel platelet products.

\section{Author affiliations}

${ }^{1}$ Department of Hematology, HAGA Teaching Hospital Den Haag, The Netherlands

${ }^{2}$ Center for Clinical Transfusion Research, Sanquin Research, Leiden, The Netherlands

${ }^{3}$ Faculty of Health Sciences, Department of Medicine, Canadian Blood Services, McMaster University, and Centre for Innovation, Hamilton, Ontario, Canada

${ }^{4}$ Leiden University Medical Centre, Leiden, The Netherlands

${ }^{5}$ Department of Clinical Epidemiology, Leiden University Medical Center, Leiden, The Netherlands

${ }^{6}$ Department of Immunology and Transfusion Medicine, and Department of Clinical Science, Haukeland University Hospital, University of Bergen, Bergen, Norway

Acknowledgements The authors thank Ray Goodrich, David Cox and Ronald Brand, for their role in the design of the PREPAReS study. This trial is being coordinated by Sanquin Research, Center for Clinical Transfusion Research and the trial is funded by Terumo BCT. The McMaster Transfusion Research Program, which is coordinating the study in the Canadian centres, receives partial infrastructure funding from Canadian Blood Services and Health Canada.

Contributors J-LHK, PFvdM, AB, JAvH and PFY were involved in conception and trial design. PFY, PFvdM and J-LHK were involved in drafting of the article. NMH, PFvdM, AB, JAvH, RAM, TS, TH and JGvdB were involved in critical revision of the article for important intellectual content. All the authors were involved in final approval of the article. TS provided statistical expertise. Preparing study design, collection, management, analysis and interpretation of data; writing of the report; and the decision to submit the report for publication is the responsibility of Sanquin, the study sponsor. The study funder, Terumo BCT, has an advisory role. Although strictly from a regulatory perspective for the Canadian part of the study, Terumo BCT is the sponsor of the trial; also, in Canada, by contract, all study related activities as mentioned are under the authority of Sanquin. 
Funding The PREPAReS study is investigator initiated; Sanquin Blood Supply is the sponsor of the study. The PREPAReS study is funded by Terumo BCT.

Competing interests None declared.

Ethics approval Central Ethics Committee: METC Zuidwest Holland, the Netherlands.

\section{Provenance and peer review Not commissioned; externally peer reviewed.}

Open Access This is an Open Access article distributed in accordance with the Creative Commons Attribution Non Commercial (CC BY-NC 4.0) license, which permits others to distribute, remix, adapt, build upon this work noncommercially, and license their derivative works on different terms, provided the original work is properly cited and the use is non-commercial. See: http:// creativecommons.org/licenses/by-nc/4.0/

\section{REFERENCES}

1. Franchini M, Frattini F, Crestani S, et al. Bleeding complications in patients with hematologic malignancies. Semin Thromb Hemost 2013;39:94-100.

2. http://www.fda.gov/ohrms/dockets/ac/transcripts/2004-4057t1.htm

3. Yomtovian R. Bacterial contamination of blood: lessons from the past and road map for the future. Transfusion 2004;44:450-60.

4. Dumont LJ, AuBuchon JP, Whitley P, et al. Seven-day storage of single-donor platelets: recovery and survival in an autologous transfusion study. Transfusion 2002;42:847-54.

5. Dijkstra-Tiekstra MJ, Pietersz RN, Hendriks EC, et al. In vivo PLT increments after transfusions of WBC-reduced PLT concentrates stored for up to 7 days. Transfusion 2004;44:330-6.

6. Koopman MM, van't Ende E, Lieshout-Krikke R, et al. Bacterial screening of platelet concentrates: results of 2 years active surveillance of transfused positive cultured units released as negative to date. Vox Sang 2009;97:355-7.

7. Bihl F, Castelli D, Marincola F, et al. Transfusion-transmitted infections. J Transl Med 2007;5:25.

8. Salunkhe V, van der Meer PF, de Korte D, et al. Development of blood transfusion product pathogen reduction treatments: a review of methods, current applications and demands. Transfus Apher Sci 2015;52:19-34.

9. Butler C, Doree C, Estcourt LJ, et al. Pathogen-reduced platelets for the prevention of bleeding. Cochrane Database Syst Rev 2013;(3): CD009072.

10. Pietersz RN, Reesink HW, Panzer S, et al. Bacterial contamination in platelet concentrates. Vox Sang 2014;106:256-83.

11. Li J, de Korte D, Woolum MD, et al. Pathogen reduction of buffy coat platelet concentrates using riboflavin and light: comparisons with pathogen-reduction technology-treated apheresis platelet products. Vox Sang 2004;87:82-90.

12. Ruane PH, Edrich R, Gampp D, et al. Photochemical inactivation of selected viruses and bacteria in platelet concentrates using riboflavin and light. Transfusion 2004;44:877-85.

13. Goodrich RP, Gilmour D, Hovenga N, et al. A laboratory comparison of pathogen reduction technology treatment and culture of platelet products for addressing bacterial contamination concerns. Transfusion 2009;49:1205-16.

14. Mirasol Clinical Evaluation Study Group. A randomized controlled clinical trial evaluating the performance and safety of platelets treated with MIRASOL pathogen reduction technology. Transfusion 2010;50:2362-75.

15. No authors listed]. Leukocyte reduction and ultraviolet B irradiation of platelets to prevent alloimmunization and refractoriness to platelet transfusions. The Trial to Reduce Alloimmunization to Platelets Study Group. N Engl J Med 1997;37:1861-9.

16. Efird J. Blocked randomization with randomly selected block sizes. Int J Environ Res Public Health 2011;8:15-20.

17. Scharfstein DO, Tsiatis AA, Robins JM. Semiparametric efficiency and its implication on the design and analysis of group-sequential. J Am Stat Assoc 1997;92:1342-50.

18. McDonald CP, Roy A, Lowe $\mathrm{P}$, et al. Evaluation of the BacT/Alert automated blood culture system for detecting bacteria and measuring their growth kinetics in leucodepleted and non-leucodepleted platelet concentrates. Vox Sang 2001;81:154-60.

19. McCullough J, Vesole DH, Benjamin RJ, et al. Therapeutic efficacy and safety of platelets treated with a photochemical process for pathogen inactivation: the SPRINT Trial. Blood 2004;104:1534-41.

20. Murphy S, Snyder E, Cable R, et al. SPRINT Study Group. Platelet dose consistency and its effect on the number of platelet transfusions for support of thrombocytopenia: an analysis of the
SPRINT trial of platelets photochemically treated with amotosalen $\mathrm{HCl}$ and ultraviolet A light. Transfusion 2006;46:24-33.

21. CBO, Kwaliteitsinstituut voor de Gezondheidszorg. Richtlijn Bloedtransfusie. Utrecht, 2004. http://nvic.nl/sites/default/files/CBO\% 20Richtlijn\%20Bloedtransfusie.pdf

22. Slichter SJ. Relationship between platelet count and bleeding risk in thrombocytopenic patients. Transfus Med Rev 2004:18:153-67.

23. Friedmann AM, Sengul $\mathrm{H}$, Lehmann $\mathrm{H}$, et al. Do basic laboratory tests or clinical observations predict bleeding in thrombocytopenic oncology patients? A reevaluation of prophylactic platelet transfusions. Transfus Med Rev 2002;16:34-45.

24. Estcourt LJ, Heddle N, Kaufman R, et al, Biomedical Excellence for Safer Transfusion Collaborative. The challenges of measuring bleeding outcomes in clinical trials of platelet transfusions. Transfusion 2013:53:1531-43.

25. Heddle NM, Cook RJ, Tinmouth A, et al., SToP Study Investigators of the BEST Collaborative. A randomised controlled trial comparing standard- and low-dose strategies for transfusion of platelets (SToP) to patients with thrombocytopenia. Blood 2009;113:1564-73.

26. Slichter SJ, Kaufman RM, Assmann SF, et al. Dose of prophylactic platelet transfusions and prevention of hemorrhage. $N$ Engl $\mathrm{J}$ Med 2010;362:600-13

27. Stanworth SJ, Estcourt LJ, Powter G, et al., TOPPS Investigators. A no-prophylaxis platelet-transfusion strategy for hematologic cancers. N Engl J Med 2013;368:1771-80.

28. Wandt H, Schaefer-Eckart K, Wendelin K, et al., Study Alliance Leukemia. Therapeutic platelet transfusion versus routine prophylactic transfusion in patients with haematological malignancies: an open-label, multicentre, randomised study. Lancet 2012;380:1309-16.

29. Ypma PF, Kerkhoffs JL, van Hilten JA, et al. The observation of bleeding complications in haemato-oncological patients: stringent watching, relevant reporting. Transfus Med 2012;22:426-31.

30. Hanson SR, Slichter SJ. Platelet kinetics in patients with bone marrow hypoplasia: evidence for a fixed platelet requirement. Blood 1985;66:1105-9.

31. Goodrich RP, Li J, Pieters $\mathrm{H}$, et al. Correlation of in vitro platelet quality measurements with in vivo platelet viability in human subjects. Vox Sang 2006;90:279-85.

32. Slichter SJ, Corson J, Jones MK, et al. Exploratory studies of extended storage of apheresis platelets in a platelet additive solution (PAS). Blood 2014;123:271-80.

33. van der Meer PF, Kerkhoffs JL, Curvers J, et al. In vitro comparison of platelet storage in plasma and in four platelet additive solutions, and the effect of pathogen reduction: a proposal for an in vitro rating system. Vox Sang 2010;98:517-24.

34. Rinder HM, Murphy M, Mitchell JG, et al. Progressive platelet activation with storage: evidence for shortened survival of activated platelets after transfusion. Transfusion 1991;31:409-14.

35. Michelson AD, Barnard MR, Hechtman HB, et al. In vivo tracking of platelets: circulating degranulated platelets rapidly lose surface $\mathrm{P}$-selectin but continue to circulate and function. Proc Natl Acad Sci USA 1996;93:11877-82.

36. Berger G, Hartwell DW, Wagner DD. P-selectin and platelet clearance. Blood 1998;92:4446-52.

37. Leytin V, Allen DJ, Gwozdz A, et al. Role of platelet surface glycoprotein Ibalpha and P-selectin in the clearance of transfused platelet concentrates. Transfusion 2004;44:1487-95.

38. Pereira J, Soto M, Palomo I, et al. Platelet aging in vivo is associated with activation of apoptotic pathways: studies in a model of suppressed thrombopoiesis in dogs. Thromb Haemost 2002;87:905-9.

39. Rand ML, Wang H, Bang KW, et al. Procoagulant surface exposure and apoptosis in rabbit platelets: association with shortened survival and steady-state senescence. J Thromb Haemost 2004;2:651-9.

40. D'Aurelio M, Merlo Pich M, Catani L, et al. Decreased Pasteur effect in platelets of aged individuals. Mech Ageing Dev 2001;122:823-33.

41. Bertolini F, Porretti L, Lauri E, et al. Role of lactate in platelet storage lesion. Vox Sang 1993;65:194-8.

42. Maurer-Spurej E, Labrie A, Pittendreigh C, et al. Platelet quality measured with dynamic light scattering correlates with transfusion outcome in hematologic malignancies. Transfusion 2009;49:2276-84.

43. Asano $\mathrm{H}$, Lee $\mathrm{CY}$, Fox-Talbot $\mathrm{K}$, et al. Treatment with riboflavin and ultraviolet light prevents alloimmunization to platelet transfusions and cardiac transplants. Transplantation 2007;84:1174-82.

44. Marschner S, Fast LD, Baldwin WM III, et al. White blood cell inactivation after treatment with riboflavin and ultraviolet light. Transfusion 2010;50:2489-98. 
45. Slichter SJ, Pellham E, Lawrence Bailey S, et al. Filtration leukoreduction followed by pathogen-reduction (Mirasol Treatment) prevents alloimmune platelet refractoriness in a dog platelet transfusion model [abstract]. Blood 2012;120:Abstract 271.

46. Jackman RP, Heitman JW, Marschner S, et al. Understanding loss of donor white blood cell immunogenicity after pathogen reduction: mechanisms of action in ultraviolet illumination and riboflavin treatment. Transfusion 2009;49:2686-99.

47. Fast LD, Dileone G, Li J, et al. Functional inactivation of white blood cells by Mirasol treatment. Vox Sang 2010;98:517-24.

48. Endres RO, Kleinman SH, Carrick DM, et al. National Heart, Lung, and Blood Institute Retrovirus Epidemiology Donor Study-II. Identification of specificities of antibodies against human leukocyte antigens in blood donors. Transfusion 2010;50:1749-60.

49. Romanov YA, Chervontseva AM, Savchenko VG, et al. Vascular endothelium: target or victim of cytostatic therapy? Can J Physiol Pharmacol 2007;85:396-403.

50. de Vos FY, Willemse PH, de Vries EG, et al. Endothelial cell effects of cytotoxics: balance between desired and unwanted effects. Cancer Treat Rev 2004;30:495-513.

51. Moore IM, Merkle CJ, Miketova $\mathrm{P}$, et al. Cytosine arabinoside induces programmed endothelial cell death through the caspase-3 pathway. Biol Res Nurs 2006;7:289-96.

52. Nachman RL, Rafii S. Platelets, petechiae, and preservation of the vascular wall. N Engl J Med 2009;359:1261-70.

53. Rizvi AA. Cytokine biomarkers, endothelial inflammation, and atherosclerosis in the metabolic syndrome: emerging concepts. Am J Med Sci 2009;338:310-18.
54. Satchell SC, Tooke JE. What is the mechanism of microalbuminuria in diabetes: a role for the glomerular endothelium? Diabetologica 2008;51:714-25.

55. Blajchman MA, Vamvakas EC. The continuing risk of transfusion-transmitted infections. N Engl J Med 2006; 355:1303-5.

56. Bernardin F, Operskalski E, Busch M, et al. Transfusion transmission of highly prevalent commensal human viruses. Transfusion 2010;50:2474-83.

57. Webert KE, Cook RJ, Couban S, et al. A study of the agreement between patient self-assessment and study personnel assessment of bleeding symptoms. Transfusion 2006;46:1926-33.

58. Middelburg RA, Ypma PF, van der Meer PF, et al. Measuring clinical bleeding using a standardized daily report form and a computer algorithm for adjudication of WHO bleeding grades. Vox Sang 2013;105:144-9.

59. Keil SD, Bengrine A, Bowen R, et al. Inactivation of viruses in platelet and plasma products using a riboflavin-and-UV-based photochemical treatment. Transfusion 2015;55:1736-44.

60. Webert K, Cook RJ, Sigouin CS, et al. The risk of bleeding in thrombocytopenic patients with acute myeloid leukemia. Haematologica 2006;91:1530-7.

61. Heddle NM, Arnold DM, Webert KE. Time to rethink clinically important outcomes in platelet transfusion trials. Transfusion 2011;51:430-4.

62. Webert KE, Arnold DM, Lui Y, et al. A new tool to assess bleeding severity in patients with chemotherapy-induced thrombocytopenia. Transfusion 2012;52:2466-74. 